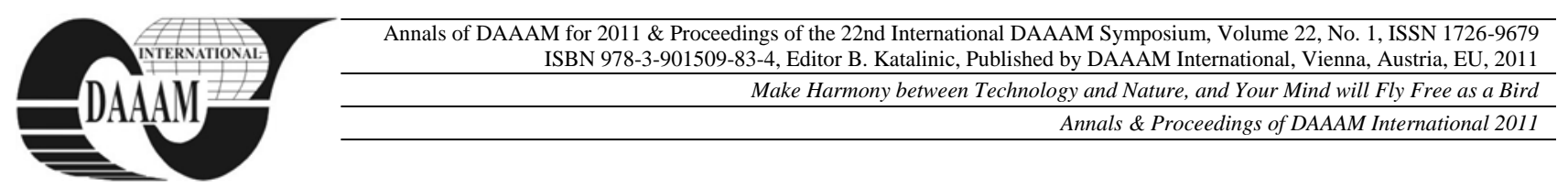

\title{
PRESENT SITUATION OF INTEGRATED LOGISTICS IN SLOVAK AUTOMOTIVE INDUSTRY
}

\author{
STANKOVSKY, P[eter] \& CIBULKA, V[iliam]
}

\begin{abstract}
This article deals with the present situation of integrated logistics in the automotive industry in Slovakia. It describes the logistics integration areas of automobile plant based, first of all, on the service utilization of logistics integrators. Information resources needed for the integrated management of logistics processes are characterized too. The main identified problems of logistics processes in the automotive industry and their possible solutions contributing to the rising level of integrated logistics are mentioned at last.

Key words: integrated logistics, automotive industry, logistics outsourcing, customer
\end{abstract}

\section{INTRODUCTION}

Integrated logistics is the last evolutionary stage of business logistics integrating all partial logistics chains in supply, production and distribution into one compact chain. Logistics becomes a co-creator of company strategy. (Pernica, 2004)

The customer is situated at the beginning and at the end of this chain. It is common that the customer puts in motion the whole supply chain by means of his order. Customer seeks more and more car variations. The management of logistics processes becomes increasingly difficult because of it. Automobile producers try to assemble the same components into several car models. Thank to it, they decrease the seriousness of material flow. For example, PSA Peugeot Citroën produces more than three thousand variations of Peugeot 207 and Citroën C3 Picasso in Trnava, but both models contain a considerable percentage of the same components.

Customer demands a flexible approach to satisfy his order from automobile producer too. He is not willing to wait for a new car for several months. He accepts a few days waiting period. In case of the insufficient flexibility of the supply chain he refers to competitors.

\section{INTEGRATED TENDENCIES IN SLOVAK AUTOMOTIVE INDUSTRY}

When automobile producers want to be able to satisfy customer's requirements they have to integrate their logistics processes with the rest of supply chain participants. Because every automobile producer in Slovakia has a few hundred suppliers, he realizes these integrating activities by means of the so-called logistics integrator. He is able to consolidate supplies from many suppliers and assure regular supplies for assembly lines. The finished car distribution and the management of transport units flows belong to his basic activities besides. He realizes mentioned supplies on the base of commercial clause ex works. Within this clause supplier has only to consign supplied components in his own store. Thenceforth supplier bears any risks and costs of transported goods. Integrator subsequently exercises control, realizes loading of components and provides for transport to the automobile plant (Incoterms ${ }^{\circledR}$ 2010).
He organizes transport in a variety of ways in regard to the character of supplies. If the truck contains only one supplier's components, the integrator realizes so-called direct. It is a direct transport between supplier and producer. If the integrator has built a net of collecting places, we talk about cross-docking. Several suppliers' components are transported to these places. Integrator subsequently makes the supply consolidation and supplies are transported to the automobile plant. In light of transport costs, so-called milk run is very advantageous. It is based on strictly defined circuits. Transport units are exchanged empty for full within them. Thank to it, trucks never run empty.

In terms of time, the transport of synchro components is most exacting. These components are characterized by big diversity and sizable proportions (wheels, seats, dashboards, fuel systems, cable kits, etc.). Their storage is inadmissible. Their supplies have to be precisely synchronized with production and do not have to wait for unloading. It is possible to connect a semitrailer straight to the assembly line.

Logistics integrator plays an important role in finished vehicle distribution too. They are generally transported for long distance. Therefore, the integrator has to be able to use the opportunities of intermodal transport. $\mathrm{He}$ assumes full responsibility for tax and customs liability. Considerable time and financial savings for the producer result from it. Integrator provides the management of transport units flows and creates standardized transport boxes designed for multiple usages. These boxes substitute one-time containers.

Logistics integrators have to utilize standardized information resources accepted by all parties in order to connect single segments of supply chains. For this purpose, socalled electronic logistics protocols are used. They are created in a few days advance for loading at the supplier. Thank to it, the producer knows beforehand that he can count on given supply. His supplier knows what he has to supply and he does not have to keep useless stocks. Logistics integrator has ample time to choose a suitable means of transport. Furthermore, the protocol contains a tool enabling to check the optimal utilization of transport capacities. Means of transport in automotive logistics are accommodated to side-loading, so electronic logistics protocols are able to illustrate their crosssections and the exact location of single components. Information about the loading times at supplier, transport times, transport lines, used standardized boxes, etc. are available for all contracting parties. Protocols take the obligatory drivers' breaks, holidays and driving bans for trucks in transported countries affecting, first of all, working Saturdays into account.

The production order is one of the next key information resources. It defines the exact parameters of produced car and is the main information base mainly for synchronized supplies. It dictates the number of produced cars, so it significantly affects transport. If Kia Motors has to increase the ratio of Sportage to Cee'd, various changes result from it. Larger components will be required and more trucks will be needed. It will necessary to revise the electronics logistics protocols, negotiate new conditions with logistics integrators and modify the standards. 


\section{PROPOSALS OF NEXT DEVELOPMENT OF INTEGRATED LOGISTICS IN SLOVAK AUTOMOTIVE INDUSTRY}

On the ground of analysis of information received from automobile producers we have identified following problems that have to be handled for the next development of logistics integration in the Slovak automotive industry:

1) Services of logistics integrators are not interesting for some of the suppliers - A certain group of suppliers, which provides supplies in its overhead, exists within the supply of automobile plants. Automobile producers are subsequently forced to categorize their suppliers. The supply chain visibility decreases because of it and logistics processes are not uniform. Suppliers' interest can be elicited only by the expansion of logistics integrators' services. They should concentrate on sub-suppliers too in order to achieve the broader effects of logistics integration.

2) Logistics concepts of automobile producers are narrowly aimed - So-called "Das Neue Logistik Konzept" from VW and "La logistique alternative" from PSA Peugeot Citroën are mainly aimed at first stage suppliers. In consequence of Modular Sourcing strategy automobile producers are supplied by complete modules. They lost contact with the original suppliers of components because of it. These are getting to the position of sub-suppliers. It is necessary to ensure access to $\mathrm{B} 2 \mathrm{~B}$ portals intended for information sharing between automobile producers and their suppliers.

3) Insufficient diversification of suppliers - Every automobile producer in Slovakia plans to increase the volume of production. VW has introduced a new project called "New Small Family". PSA Peugeot Citroën is going to switch over to the three shift operation because of the production of the new model of Peugeot 208. Kia Motors is going to produce more than 300 thousands of cars in 2012. Thank to it, its production plant will be fully utilized. We assume producers will have to proceed to the diversification of suppliers due to the deficient capacities of present suppliers. Producers will decrease present risks connected with dependence on only one supplier and new space for logistics integrators will be created because of it.

4) Insufficient information integration with suppliers - In light of integrated logistics a homogeneous information solution is absent in automotive supply chains. It is common that producers and their suppliers use different information systems. They are forced to utilize a special translator (GSX server) in consequence of it.

5) Low flexibility of logistics outsourcing contracts - Many processes are ensured by logistics outsourcing within the frame of integrated logistics. Contracts with external service providers are often passed for a long time period. It may have a negative impact on the flexibility of outsourcing partner. He adheres strictly to the contract, so he is not able to flexibly react to moving producer's requirements and his proposals relating to the optimization of processes. Employees of producer subsequently perform some activities instead of employees of outsourcing partner.

6) Insufficient flexibility of order satisfaction - If a customer orders an exactly appointed car from the car importer, waiting period may be even two weeks. Production time, i. e. way between input to the welding shop and output from the assembly, is for example in PSA Peugeot Citroën only twenty-three hours in comparison with mentioned time. Producers should concentrate on time reduction of supply and distribution processes. Free taking of car direct from production plant could be one of the first steps.

7) High range of securitization - According to available information from automobile producers, order is dispatched to suppliers (with exception synchro suppliers) in six days before material input to plant. Thank to it, the material is available for production for a period of six days. Furthermore, one more securitization is available. It achieves from four to fifteen hours in dependence on the distance of the supplier. If a producer wants to reduce the lead time, he has to reduce these times.

8) Insufficient reactive capability of information systems Production plans are generated in eight days before material input to plant. This shows that systems generating orders have two days to generate sufficient volume of orders for assurance of production requirements. It is necessary to reduce this time in order to increase the supply chain flexibility

9) Enforcement of System Sourcing strategy - Automobile producers permanently decrease the depth of production and increasingly concentrate on assembly. It comes to the transition of generated value from producers to suppliers. Producers have to transfer more competencies on suppliers. Consignment stocks belong to the first steps of automobile producers in this area. These stocks are managed by the supplier and are intended for storage of coil sheet needed for the pressing shop and for storage of chemicals needed for paint shop. Suppliers become the carrier of know-how, innovation potential, quality and rising utility value. For that reason, producers have to involve suppliers in the processes of research and development, preparation of production and assurance of rising customer requirements.

\section{CONCLUSION}

We are conscious that the proposals for these problems solving have to go from the decisions of foreign centers of automobile concerns. It will be a long-term process. Its timing is very important. On our opinion, the modification of the product portfolio and the introduction of technology innovations in the Slovak automotive industry is an opportune moment. The contribution resulting from development of the integrated logistics concept will be observable in mechanical engineering, electrical engineering, plastic production, rubber industry, etc. on the score of interconnection with other industries. Thank to it, Slovakia could achieve a positive effect on the gross domestic product formation, the trade balance deficit decreasing and employment rate increasing.

Our future research plans are connected with research in other industries in Slovakia. We are going to scan their level of integrated logistics by using the managed interview and the electronic questionnaire. The obtained information will be used for the creation of new methodology for increasing the level of integrated logistics. The mentioned methodology will become an important part of dissertation thesis, called "Integrated Logistics as the Base of Raising Company Competitiveness".

\section{REFERENCES}

ICC. (2010). Incoterms ${ }^{\circledR}$ 2010. Paris: International Chamber of Commerce, ISBN: 978-92-8420080-1

Kerjan, J. A. (2004). Évolution des modes de fonctionnement PSA-DIFA Europe. Available from: $\mathrm{http} / / / \mathrm{www} . g a l i a . c o m / g a l i a \_v i s u e l s /$ evenements/51/cr_47.p df, Accessed on: 2011-05-10

Pernica, P. (2004). Logistika (Supply Chain management) pro 21. století. Praha: Radix spol. s r.o., p. 638, ISBN 8086031-59-4

Viestová, K. (2007). Lexikón logistiky. Bratislava: Iura Edition, p. 65, ISBN: 978-80-8078-160-6

Wagner, H. \& Balázs, J. (2009). Das Neue Logistik Konzept (NLK) des Volkswagen Konzerns auf Basis SAP am Beispiel des Pickup-Sheet-Prozesses. Available from: http://www.sap.com/germany/services/consulting/acs/custo mersuccess/FaVW+AUDI_SAP_ACS_PUS_090923_DE.p df, Accessed on: 2011-05-10 